\title{
HIGH POWER TEST OF THE PROTOTYPE CRYOMODULE FOR ADS SUPERCONDUCTING LINAC
}

\author{
E. Kako", S. Noguchi, N. Ohuchi, T. Shishido and K. Tsuchiya \\ KEK, Tsukuba, Ibaraki, 305-0801, JAPAN
}

\author{
N. Akaoka, E. Chishiro, T. Hori, H. Kobayashi, M. Nakata, N. Ouchi and M. Yamazaki \\ JAERI, Tokai, Ibaraki, 319-1195, JAPAN
}

\begin{abstract}
A prototype cryomodule containing two 9-cell superconducting cavities of $\beta=0.725$ and $\mathrm{fo}=972 \mathrm{MHz}$ had been constructed under the collaboration of Japan Atomic Energy Research Institute (JAERI) and High Energy Accelerator Research Organization (KEK) on the development of superconducting LINAC for Accelerator Driven System (ADS). Cool-down tests to $2 \mathrm{~K}$ of the cryomodule and high power rf tests with a $972 \mathrm{MHz}$ pulsed klystron have been carried out. Rf power of $350 \mathrm{~kW}$ in pulsed operation of $3 \mathrm{msec}$ and $25 \mathrm{~Hz}$ was transferred to a nine-cell cavity through an input coupler. Accelerating gradients of $14 \mathrm{MV} / \mathrm{m}$ higher than the specification of $10 \mathrm{MV} / \mathrm{m}$ have been achieved in both cavities. Compensation of Lorentz-force detuning by a piezo tuner was successfully demonstrated.
\end{abstract}

\section{INTRODUCTION}

Construction of the J-PARC (Japan Proton Accelerator Research Complex) is being carried out aiming at the commissioning in 2007, [1]. The $181 \mathrm{MeV}$ linac section, which consists of normal conducting accelerating structures, will be completed in 2006. A superconducting linac will be added in the second phase of the project, and the $600 \mathrm{MeV} \mathrm{H}^{-}$beams will be delivered to the ADS experimental facility. The R\&D work on superconducting linac for ADS is being continued in collaboration with JAERI and KEK. A prototype cryomodule with $\beta=0.725$ $(424 \mathrm{MeV})$ was designed and constructed, [2]. The first cool-down test of the cryomodule was successfully carried out last year, and the cryogenic performance at $2 \mathrm{~K}$ and the rf property with low power were reported in $[3,4]$. In the successive tests, high power rf system consisting of a $972 \mathrm{MHz}$ pulsed klystron, waveguides, circulators and dummy loads were prepared to study a high gradient operation in a pulsed mode. High field performance of the cavities and observation of mechanical vibration and Lorentz-force detuning in pulsed operation are described in this paper.

\section{CRYOMODULE}

Typical design parameters of the prototype cryomodule are listed in Table 1. The cryomodule includes two $972 \mathrm{MHz}$ nine-cell niobium cavities, which rf parameters are summarised in Table 2. Two cavities named R (right-

\#eiji.kako@kek.jp side) and L (left-side) are made of niobium sheets of $4 \mathrm{~mm}$ thick with RRR 250, in order to provide a sufficient stiffness without stiffening rings and to suppress Lorentzforce detuning. The niobium cavity is covered with a titanium jacket of $6 \mathrm{~mm}$ thick for filling liquid $\mathrm{He}$ of $2 \mathrm{~K}$. Endplates of the He vessel have an optimised shape and thickness so as to obtain a required stiffness of $50 \mathrm{kN} / \mathrm{mm}$.

A cavity tuning system consisting of a stepping motor and a piezo electric transducer is installed outside of the vacuum vessel. Each cavity has a pair of the tuning system, (a piezo is only at one side). Tuning force through two coaxial transmitters drives between both thick endplates of titanium bellows attached at the He vessel. The measured tuning sensitivity and stroke were $200 \mathrm{kHz} / \mathrm{mm}$ and $10 \mathrm{~mm}$ in the motor tuner, and $100 \mathrm{~Hz} / \mu \mathrm{m}$ and $30 \mu \mathrm{m}$ in the piezo tuner, $(\max .1 .0 \mathrm{kV})$. The elastic constant of the cavity was $1300 \mathrm{~N} / \mathrm{mm}$.

Experimental set-up for the high power test is shown in Figure 1. The prototype cryomodele and a valve box surrounded with radiation shields, a waveguide system, transfer tubes and a liquid He-Dewar are shown.

Table 1: Design parameters of the cryomodule.

\begin{tabular}{|l|l|l|}
\hline Pulsed Operation & $3.0 \mathrm{msec}$ & $25 \mathrm{~Hz}$ \\
\hline Beam Current & 30. & $\mathrm{~mA}$ \\
\hline Temperature & 2. & $\mathrm{~K}$ \\
\hline Eacc & 10. & $\mathrm{MV} / \mathrm{m}$ \\
\hline Qo & $>1 . \times 10^{10}$ & \\
\hline Input RF power & 300. & $\mathrm{~kW}$ \\
\hline Qext (Input) & $5 . \times 10^{5}$ & \\
\hline
\end{tabular}

Table 2: RF parameters of a 9-cell cavity.

\begin{tabular}{|l|l|l|}
\hline Esp/Eacc & 3.07 & \\
\hline Hsp/Eacc & 55.4 & Oe/MV/m \\
\hline R/Q & 478. & $\Omega$ \\
\hline Geometrical factor & 208. & $\Omega$ \\
\hline Cell-to-cell coupling & 2.80 & $\%$ \\
\hline & & \\
\hline &
\end{tabular}

Figure 1: Experimental set-up for the high power test. 


\section{HIGH FIELD PERFORMANCE}

Rf processing of two input couplers was previously carried out at a test stand up to $1.0 \mathrm{MW}$ with $0.6 \mathrm{msec}$ and $50 \mathrm{~Hz},[5]$. After installation in the cryomodule, the input couplers were baked out at $120^{\circ} \mathrm{C}$ for 40 hours. Then, rf processing at room temperature was carried out up to $\mathrm{rf}$ input power of $350 \mathrm{~kW}$ with $3.0 \mathrm{msec}$ and $25 \mathrm{~Hz}$ for about 10 hours in each coupler.

High power test of the cavities was initially carried out at $4.2 \mathrm{~K}$, and the first quench was observed at an accelerating gradient $(E a c c)$ of about $9 \mathrm{MV} / \mathrm{m}$ in both cavities. Through a short pulse processing of $0.6 \mathrm{msec}$, an Eacc of $14 \mathrm{MV} / \mathrm{m}$ was finally achieved within 10 hours. Further increase of the Eacc was stopped by heavy x-ray radiation due to field emission. After cool-down to $2.1 \mathrm{~K}$, a stable operation at $12 \mathrm{MV} / \mathrm{m}$ higher than the specification was confirmed in both cavities, as seen in Figure 2. In these tests, the high power rf system had been operated without a feedback control of an amplitude and a phase of the rf input power ( $P$-inp).

Measured Qo values at $2.1 \mathrm{~K}$ and $4.2 \mathrm{~K}$ are shown in Figure 3. The drop of the measured Qo from the black line at $2.1 \mathrm{~K}$ means electron loading due to field emission.
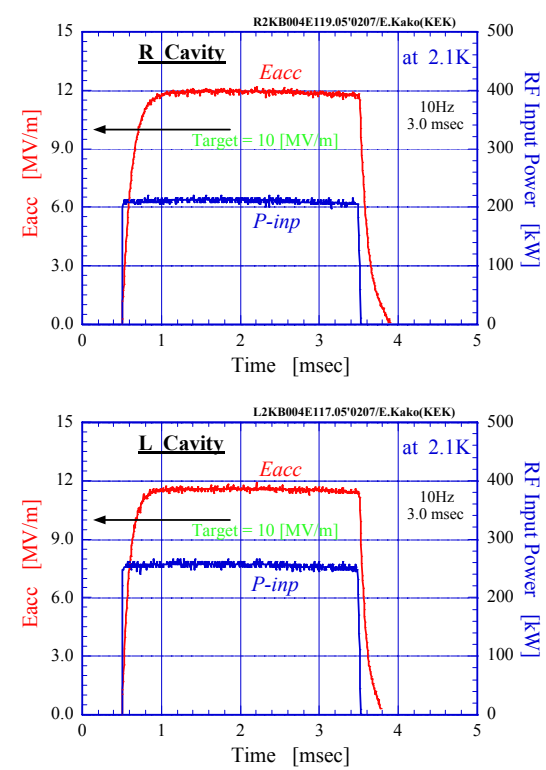

Figure 2: Achievement of target values in both cavities.

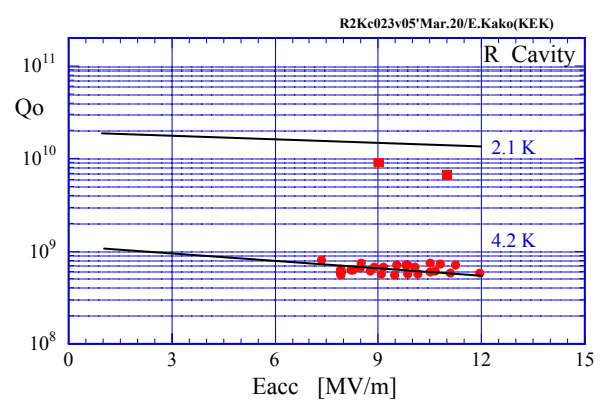

Figure 3: Qo value measured with flow rate of evaporated $\mathrm{He}$ gases in pulsed operation of $25 \mathrm{~Hz}$. Black lines were deduced from a theoretical estimation, Rres $=10 \mathrm{n} \Omega$.

\section{MECHANICAL VIBRATION}

Typical mechanical vibration modes in pulsed operation are summarised in Table 3. The characterised deformation pattern in each mode is shown in Figure 4. Several vibration modes were observed by a measurement using two piezos, of which one is an active oscillator and another is a sensor of deformation. The frequencies measured by a resonant condition with a vibration mode were consistent with the calculation, [6].

Mechanical vibrations caused by repeated rf pulses were detected by a piezo, as shown in Figure 5. Here, the $\mathrm{R}$ cavity was operated at $10 \mathrm{MV} / \mathrm{m}$, and there was no $\mathrm{rf}$ input power in the L cavity. The frequency of the dominant vibration mode was $160 \mathrm{~Hz}(150 \mathrm{~Hz})$ in the $10 \mathrm{~Hz}$ $(25 \mathrm{~Hz})$ operation by FFT analysis of the signal. The frequency is close to the second multi-cell mode, (No.2).

Table 3: Typical mechanical vibration modes.

\begin{tabular}{|c|l|c|c|}
\hline No. & Mode & Calculation & Measurement \\
\hline 1 & multi-cell (I) & $86 \mathrm{~Hz}$ & $81 \mathrm{~Hz}$ \\
\hline 2 & multi-cell (II) & $169 \mathrm{~Hz}$ & $179 \mathrm{~Hz}$ \\
\hline 3 & multi-cell (III) & $244 \mathrm{~Hz}$ & $227 \mathrm{~Hz}$ \\
\hline 4 & tuner mode (I) & $294 \mathrm{~Hz}$ & $304 \mathrm{~Hz}$ \\
\hline 41 & single-cell (II) & $3.91 \mathrm{kHz}$ & --- \\
\hline
\end{tabular}

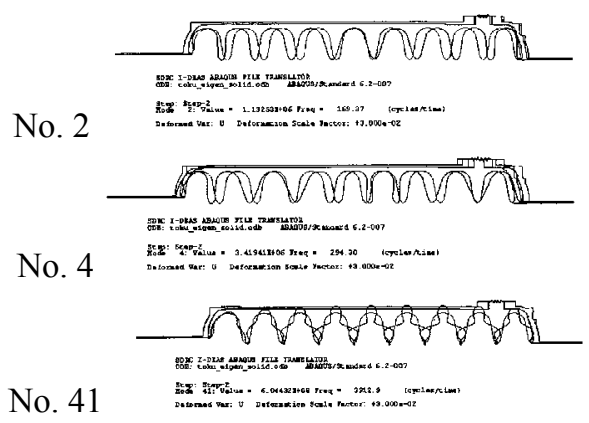

Figure 4: Patterns of mechanical vibration modes, [6].

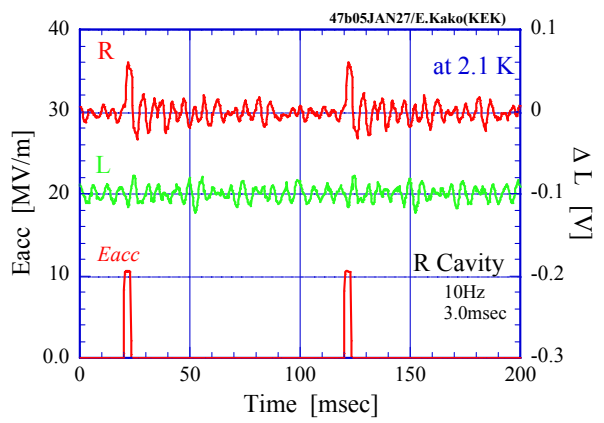

Figure 5: Mechanical vibrations due to rf pulse of $10 \mathrm{~Hz}$.

\section{LORENTZ-FORCE DETUNING}

$\mathrm{Rf}$ electromagnetic field in pulsed operation causes a deformation of a 9-cell cavity, so that the resonant frequency shifts with a proportional decrease to Eacc $^{2}$. Figure 6 shows rf pulse signals (Eacc, input power and reflected power) operated at $12 \mathrm{MV} / \mathrm{m}$ in the R cavity. The lower figure shows a phase shift between an input and a cavity's monitor signal, and deformation $(\Delta \mathrm{L})$ of a cavity 
length detected by a piezo tuner. The observed phase shift between the beginning and the end of the pulse was $-6.5^{\circ}$, which is equivalent to the detuning frequency of $-175 \mathrm{~Hz}$ with the cavity's bandwidth of $3.0 \mathrm{kHz}$. The influence to the Eacc is a slight decrease of only $0.6 \%$, so that no obvious change is seen in the Eacc signal.

A frequency shift $(\Delta \mathrm{f})$ and deformation $(\Delta \mathrm{L})$ of a cavity length due to Lorentz-force detuning was systematically investigated, as shown in Figure 7. Calibration of $\Delta \mathrm{L}$ $[\mathrm{mV}]$ to the length $[\mu \mathrm{m}]$ is under consideration. With their plots to $\mathrm{Eacc}^{2}$, following linear relations were obtained: $\Delta \mathrm{f}[\mathrm{Hz}]=-1.2 * \operatorname{Eacc}^{2}\left[\mathrm{MV}^{2} / \mathrm{m}^{2}\right]$ and $\Delta \mathrm{L}[\mathrm{mV}]=-0.5 *$ $\operatorname{Eacc}^{2}\left[\mathrm{MV}^{2} / \mathrm{m}^{2}\right]$. The obtained coefficient in $\Delta \mathrm{f}$ was nearly equal to the result in a calculated dynamic Lorentzforce detuning $(-130 \mathrm{~Hz}$ at $10 \mathrm{MV} / \mathrm{m}),[6]$.
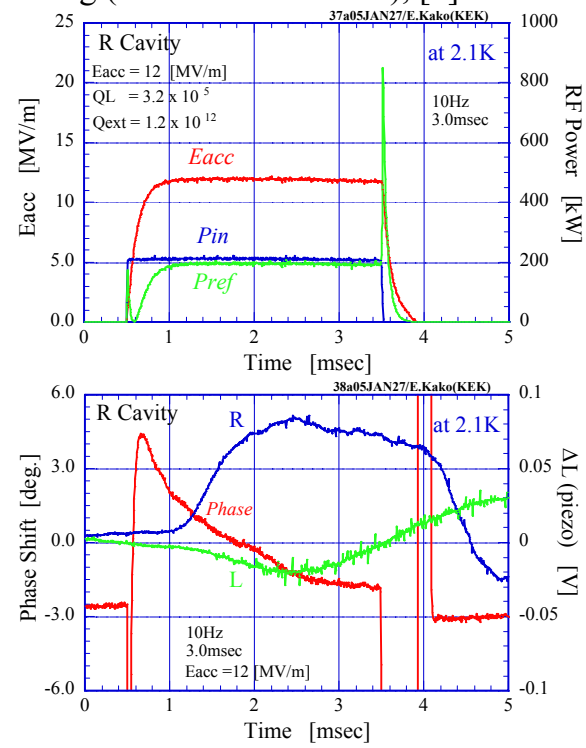

Figure 6: RF pulse signals (upper). Phase shift and deformation of a cavity length (lower).
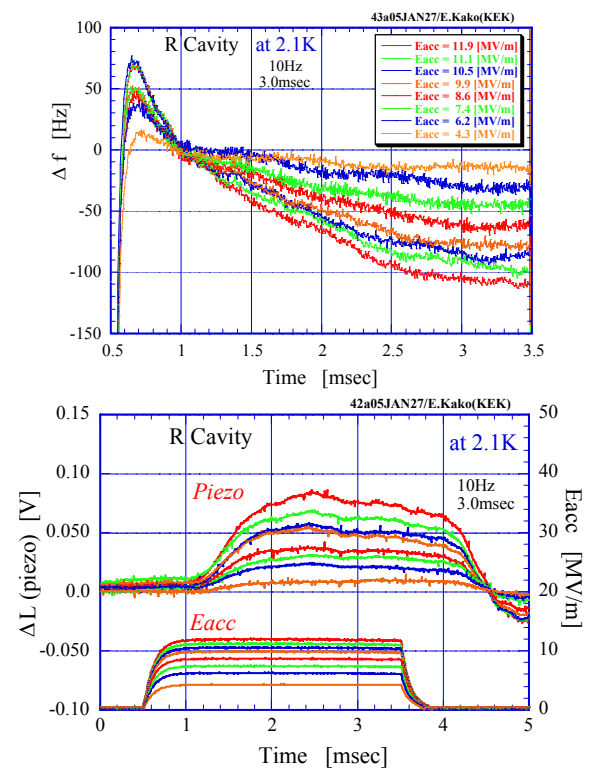

Figure 7: Frequency shift (upper) and deformation of a cavity length (lower) due to Lorentz-force detuning.

\section{COMPENSATION BY PIEZO TUNER}

A piezo tuner with a pulsed voltage can change dynamically a cavity length by a few $\mu \mathrm{m}$. As shown in Figure 8, a phase shift due to Lorentz-force detuning at $10 \mathrm{MV} / \mathrm{m}$ was successfully compensated by a piezo tuner. Mechanical response from a piezo tuner to a cavity is not so fast that there is no change in a phase shift during ramp-up. Moreover, fast components with several $\mathrm{kHz}$ like a single-cell mode (see, No.41 in Figure 4) are considered to mainly contribute to the deformation during ramp-up.

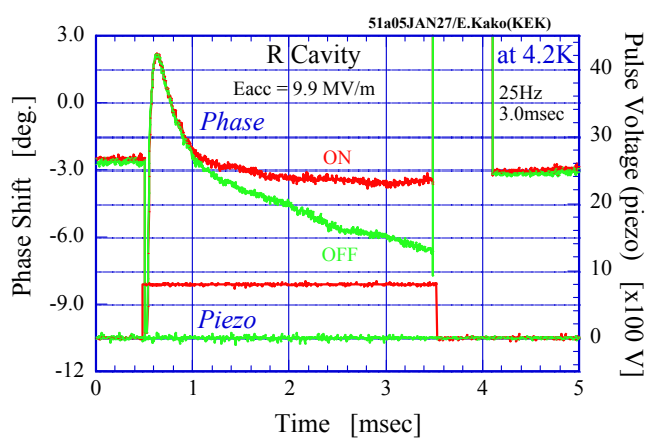

Figure 8: Compensation of Lorentz-force detuning.

\section{SUMMARY}

Accelerating gradients of $12 \mathrm{MV} / \mathrm{m}$ higher than the specification had been stably achieved in pulsed operation at $2.1 \mathrm{~K}$. Lorentz-force detuning in pulsed operation was systematically investigated, and mechanical vibration modes were measured. Compensation of Lorentz-force detuning by a piezo tuner was successfully demonstrated.

\section{ACKNOWLEDGEMENTS}

This work was supported by Ministry of Education, Culture, Sports, Science and Technology.

\section{REFERENCES}

[1] K. Hasegawa, "J-PARC Commissioning Results", in this conference, (ROPC002).

[2] S. Noguchi, E. Kako et al, "Prototype Cryomodule for the ADS Linac", Proc. of SRF2003, Luebeck/ Travemuende, Germany, (2003) MoP032.

[3] N. Ohuchi et al., "Cryogenic Performance of the Prototype Cryomodule for ADS Superconducting Linac", Proc. of EPAC2004, Lucerne, Switzerland, (2004) p1033-1035.

[4] E. Kako et al., "RF Property of the Prototype Cryomodule for ADS Superconducting Linac", Proc. of EPAC2004, Lucerne, Switzerland, (2004) p10421044.

[5] E. Kako et al., "High Power RF Tests on Input Couplers for $972 \mathrm{MHz}$ Superconducting Cavities in the J-PARC Project", Proc. of PAC2003, Portland, Oregon, U.S.A. (2003) p1338-1340.

[6] Calculation by Toshihiro Ohtani from MELCO, Japan. 